\title{
Sentidos da inclusão de alunos com deficiência na educação superior: olhares a partir da Universidade Federal de Juiz de Fora
}

\author{
José Guilherme de Andrade Almeida \\ Universidade Federal de Juiz de Fora - Juiz de Fora - MG - Brasil \\ Eliana Lucia Ferreira \\ Universidade Federal de Juiz de Fora - Juiz de Fora - MG - Brasil
}

\begin{abstract}
Resumo
Esta pesquisa tem como objetivo discutir o processo de inclusão de alunos com deficiência na educação superior brasileira, com especial foco nos sentidos mobilizados por esta inclusão nos discursos ali circulantes. Com caráter exploratório-descritivo, nos valemos da Análise de Discurso na ótica francesa para explorar o processo de produção de sentidos nas estatísticas oficias sobre esta inclusão no Brasil e em uma instituição federal de educação superior, realizando ainda, entrevistas com alunos autodeclarados com deficiência e demais sujeitos que com esses se relacionam no cotidiano universitário. Com as análises empreendidas, identificamos falhas nos dados oficiais sobre a presença de alunos com deficiência na educação superior brasileira, relacionadas tanto a ausência de mecanismos para levantamento desses dados na instituição base, quanto ao não reconhecimento da condição de deficiência por parte dos alunos que a possuem. Já em relação aos sentidos de sua inclusão, esta tem sido avaliada pelos sujeitos da educação superior enquanto presença ou enquanto provimento de condições de acessibilidade arquitetônica, indicando um despreparo e um desconhecimento para o provimento de condições de permanência para este aluno na educação superior, perpetuando barreiras à sua participação em igualdade de condições.
\end{abstract}

Palavras-chave: Educação inclusiva; deficiência; ensino superior;

\section{Sense of inclusion of students with disabilities in higher education: looks} from the Federal University of Juiz de Fora

\begin{abstract}
This research aims to discuss the process of inclusion of students with disabilities in Brazilian higher education, with a special focus on the senses mobilized by this inclusion in the circulating discourses. With an exploratory-descriptive character, we use the Discourse Analysis from the French perspective to explore the process of meaning production in the official statistics on this inclusion in Brazil and in a federal institution of higher education, also conducting interviews with self-declared students with disabilities and other subjects that with these are related in the daily life of the university. With the analyzes undertaken, we identified flaws in the official data on the presence of students with disabilities in Brazilian higher education, related both to the absence of mechanisms to collect these data in the base institution, and to the non-recognition of the deficiency condition by students that have. Regarding the meanings of their inclusion, this has been evaluated by the subjects of higher education as a presence or as a provision of architectural accessibility, indicating a lack of preparation and lack of knowledge for the provision of conditions of permanence for this student in higher education, perpetuating barriers to their participation on equal terms.
\end{abstract}

Keywords: Inclusive education; disability; higher education;

\section{Sentidos de la inclusión de alumnos con deficiencia en la educación superior: miradas a partir de la Universidad Federal de Juiz de Fora}

\section{Resumen}

En esta investigación se tiene como objetivo, discutir el proceso de inclusión de alumnos con deficiencia en la educación superior brasileña, con especial enfoque a los sentidos movilizados por esta inclusión en los discursos allí circulantes. Con carácter exploratorio-descriptivo, nos valemos del Análisis de Discurso en la óptica francesa para explorar el proceso de producción de sentidos en las estadísticas oficias sobre esta inclusión en Brasil y en una institución federal de educación superior, realizando aun, entrevistas con alumnos auto declarados con deficiencia y demás sujetos que con estos se relacionan en el cotidiano universitario. Con los análisis emprendidos, identificamos fallas en los datos oficiales sobre la presencia de alumnos con deficiencia en la educación superior brasileña, relacionadas a ausencia de mecanismos para recopilación de estos datos en la institución base, y, también al no reconocimiento de la condición de deficiencia por parte de los alumnos que la poseen. Ya en relación a los sentidos de su inclusión, esta ha sido evaluada por los sujetos de la educación superior como presencia o como desestime de condiciones de accesibilidad arquitectónica, indicando falta de preparación y desconocimiento para el desestime de condiciones de permanencia para este alumno en la educación superior, perpetuando obstáculos a su participación en igualdad de condiciones.

Palabras clave: Educación inclusiva; deficiencia; educación superior;. 


\section{Introdução}

A universidade, na concepção de Chauí (2003), é uma instituição social e, portanto, exprime a estrutura e o modo de funcionamento da sociedade, constituindo assim, uma prática social. Como reflexo de uma sociedade marcada pelas contradições, Oliveira (2013) observa que o acesso a esse nível educacional no Brasil tem sido marcado por tensões de continuidade e rupturas na seletividade social ao longo de sua história, com prevalência de mecanismos de seleção dos melhores por méritos individuais.

Este processo não tem sido diferente para as pessoas com deficiência que, ao serem colocadas sócio-historicamente em processos de estigmatização (descrédito), segregação e exclusão, tiveram diversos direitos fundamentais negados ao longo de nossa história, inclusive, o direito à educação (Silva, 1987; Sassaki, 1999; Goffman, 2008).

Nas últimas décadas, o Brasil tem se voltado à promoção de um processo de inclusão para alunos com deficiência na educação regular, processo este direcionado principalmente pelos compromissos internacionais assumidos e pelas consequentes políticas públicas nacionais como a Declaração Mundial sobre Educação para Todos e a Declaração de Salamanca (UNESCO, 1998a; 1998b), a Convenção Internacional dos Direitos das Pessoas com Deficiência (Decreto $n^{\circ}$ 6.949, 2009), a Política Nacional de Educação Especial na Perspectiva da Educação Inclusiva (Brasil, 2007) e, mais recentemente, a Lei Brasileira de Inclusão (Lei n 13.146, 2015).

Políticas desse tipo têm como objetivo, segundo Elias (1993), assumir a função de símbolo da estrutura social para reger as relações da multiplicidade de sujeitos que a constituem. Assim, as políticas públicas brasileiras têm gradativamente se alinhado à perspectiva social da deficiência, que compreende a inclusão como um duplo movimento de adequação, da sociedade para com a pessoa com deficiência e vice-versa, exigindo que suas instituições se modifiquem a fim de atender ao ser humano na sua diversidade (Decreto $n^{\circ}$ 6.949, 2009; Lei $\left.n^{\circ} 13.146,2015\right)$.

Mas é somente no início do século XXI que encontramos as primeiras políticas públicas direcionadas especificamente para a inclusão de pessoas com deficiência na educação superior, sendo a principal delas o Programa Incluir, instituído em 2005 (Brasil, 2013). A partir de então, o número de pessoas que assume a posição-sujeito de aluno universitário com deficiência nas instituições de educação superior brasileiras vem crescendo nas estatísticas oficias.

Em contrapartida, como apontam os estudos de Rocha e Miranda (2009), Reis (2010), Anache, Rovetto e Oliveira (2014), Castro e Almeida (2014) e Mendes e Bastos (2016), as ações propostas por essas instituições têm sido bem desenvolvidas apenas nos processos seletivos (acesso à educação superior), mas são ainda pouco efetivas na permanência deste aluno com deficiência, especificamente, na sua efetiva participação em igualdade de condições aos demais alunos, já que o provimento de condições de acessibilidade tem sido insuficiente.
Sendo o espaço universitário recente no tempo histórico da sociedade brasileira - pouco mais de cem anos -, ainda apresenta múltiplas tensões. Este foi planejado para um modelo-padrão de ser humano que não comporta o sujeito com deficiência, assim como grande parte das esferas da nossa sociedade.

Apesar dos movimentos a favor da inclusão de pessoas com deficiência já vigorarem em nossa sociedade há algumas décadas (cf. Sassaki, 1999), os sentidos imputados às pessoas com deficiência como o estigma, a anomia e a incapacidade (cf. Goffman, 2008) não desaparecem simplesmente, eles continuam existindo. Como nos diz Orlandi (2001, p.130) "se um sentido é necessário, ele é possível". Mesmo que os sentidos de descrédito não possam ser expostos em práticas cotidianas, eles são deslocados, persistindo na forma como o sujeito com deficiência é incluído em nossa sociedade.

Cientes dessa realidade, vamos explorar o funcionamento dos sentidos de inclusão para o sujeito-aluno com deficiência e para os sujeitos que com ele mantém relação na educação superior, visando compreender como os sujeitos mobilizam sentidos neste nível educacional.

\section{Método}

A presente pesquisa, de caráter exploratório-descritivo, tem como objetivo compreender os sentidos da inclusão de alunos com deficiência na educação superior, a partir das estatísticas oficiais do Instituto Nacional de Estudos e Pesquisas Educacionais Anísio Teixeira (INEP) e de uma instituição de educação superior, a saber, a Universidade Federal de Juiz de Fora (UFJF), bem como, dos discursos circulantes nessa universidade.

Para esta pesquisa, nos valemos da Análise de Discurso na ótica francesa de Pêcheux (2009) e Orlandi (2013), a qual se ocupa em compreender os processos de subjetivação no discurso, ou seja, como o sujeito se constitui e produz sentidos. Compreendemos o discurso como "efeito de sentido entre locutores" (Orlandi, 2001, p.63). Uma relação social de caráter linguístico que materializa a ideologia e seus sentidos, e que é posta em funcionamento através de uma materialidade, a língua/linguagem (Orlandi, 2012).

O sujeito é, portanto, assujeitado à língua pela ideologia ${ }^{1} \mathrm{e}$ subjetiva-se na medida em que se projeta de uma situação social (empírica) para uma posição-sujeito (posição no discurso), na qual mobiliza sentidos sobre si e seu contexto social e histórico. Como nos diz Orlandi (2001, p. 99) "sujeito e sentido se constituem ao mesmo tempo, na articulação da língua com a história”.

Segundo Orlandi (2013), os sentidos mobilizados não estão prontos ou acabados, mas estão se fazendo por meio da ação da ideologia, criando relações com os senti-

1 A ideologia, na Análise de Discurso, é compreendida como uma relação imaginária estabelecida entre o sujeito e as suas condições reais (materiais) de existência. Uma relação inconsciente e estruturante que direciona a forma como esse sujeito deve significar o material (empírico) a sua volta, e que lhe é imposta quando entra nas relações sociais, ou seja, desde seu nascimento (Orlandi, 2013). 
dos já-ditos (interdiscurso) e com as condições atuais de sua produção (intradiscurso). O papel da Análise de Discurso é exatamente compreender os processos interpretativos e o funcionamento dos sentidos no discurso através de sua materialidade sócio-histórica.

Nessa perspectiva, constituímos um corpus de análise com microdados disponibilizados pelo INEP sobre a inclusão de alunos com deficiência nas instituições de educação superior brasileiras e com dados levantados pela Coordenação de Acessibilidade Educacional, Física e Informacional (CAEFI/ UFJF) em censo interno na UFJF. Estes constituem parte das condições de produção dos discursos (cf. Orlandi, 2013) circulantes na UFJF ao nos conferir informações sobre a presença de alunos com deficiência na instituição e, ao mesmo tempo, são objeto de nossa análise já que se constituem como um discurso produzido que carrega sentidos específicos.

A partir desses dados e inspirados pela metodologia utilizada por Ferreira (2003), realizamos ainda entrevistas semi-estruturadas com diferentes sujeitos que se encontram na estrutura universitária e que participam e/ou influenciam o processo inclusivo enquanto interlocutores do sujeito-aluno com deficiência, a saber: Grupo A, constituído por 20 alunos autodeclarados com deficiência na UFJF; Grupo B, constituído por 03 alunos sem deficiência que convivem com alunos com deficiência no cotidiano universitário; Grupo C,constituído por 05 professores da UFJF que possuem alunos com deficiência em suas disciplinas; Grupo D, constituído por 05 integrantes da coordenação de acessibilidade da UFJF (CAEFI/UFJF). Quanto aos alunos autodeclarados com deficiência, 08 possuem deficiência física, 04 deficiência auditiva, 05 baixa visão, 01 deficiência intelectual e 02 classificam-se com outras deficiências.

A entrevista semi-estruturada foi elaborada com três perguntas base, feitas a todos os entrevistados, a saber: (1)
Como você observa a inclusão de pessoas com deficiência na UFJF?; (2) Como você observa a relação das pessoas com e sem deficiência na UFJF?; (3) Você já teve contato com a coordenação de acessibilidade da UFJF?. Dependendo das colocações do entrevistado e do desenvolvimento da entrevista, outras perguntas foram individualmente acrescidas para aprofundar os discursos coletados e favorecer a interpretação dos sentidos postos em funcionamento por cada sujeito. Após a entrevista, seus discursos foram transcritos na íntegra e analisados à luz dos pressupostos teóricos da Análise de Discurso, buscando um olhar relacional entre os diferentes sujeitos do processo de inclusão².

A presente pesquisa foi submetida ao Comitê de Ética em Pesquisa da UFJF, recebendo aprovação com o Parecer Consubstanciado n. 1.345.618/2015.

\section{Resultados e discussões}

\section{Os números da inclusão}

Os dados do INEP (2015) evidenciam uma baixa presença de alunos com deficiência nas instituições de educação superior brasileiras, sejam elas públicas ou privadas, até anos recentes, quando os números crescem de forma contínua em ambas as modalidades institucionais:

\footnotetext{
2 A fim de preservar a identidade dos sujeitos entrevistados, seus nomes foram omitidos e os mesmos identificados por meio de uma letra referente ao grupo de análise e um número corrente individual (por exemplo, A01 para o primeiro entrevistado e que pertencia ao grupo de alunos autodeclarados com deficiência na UFJF).
}

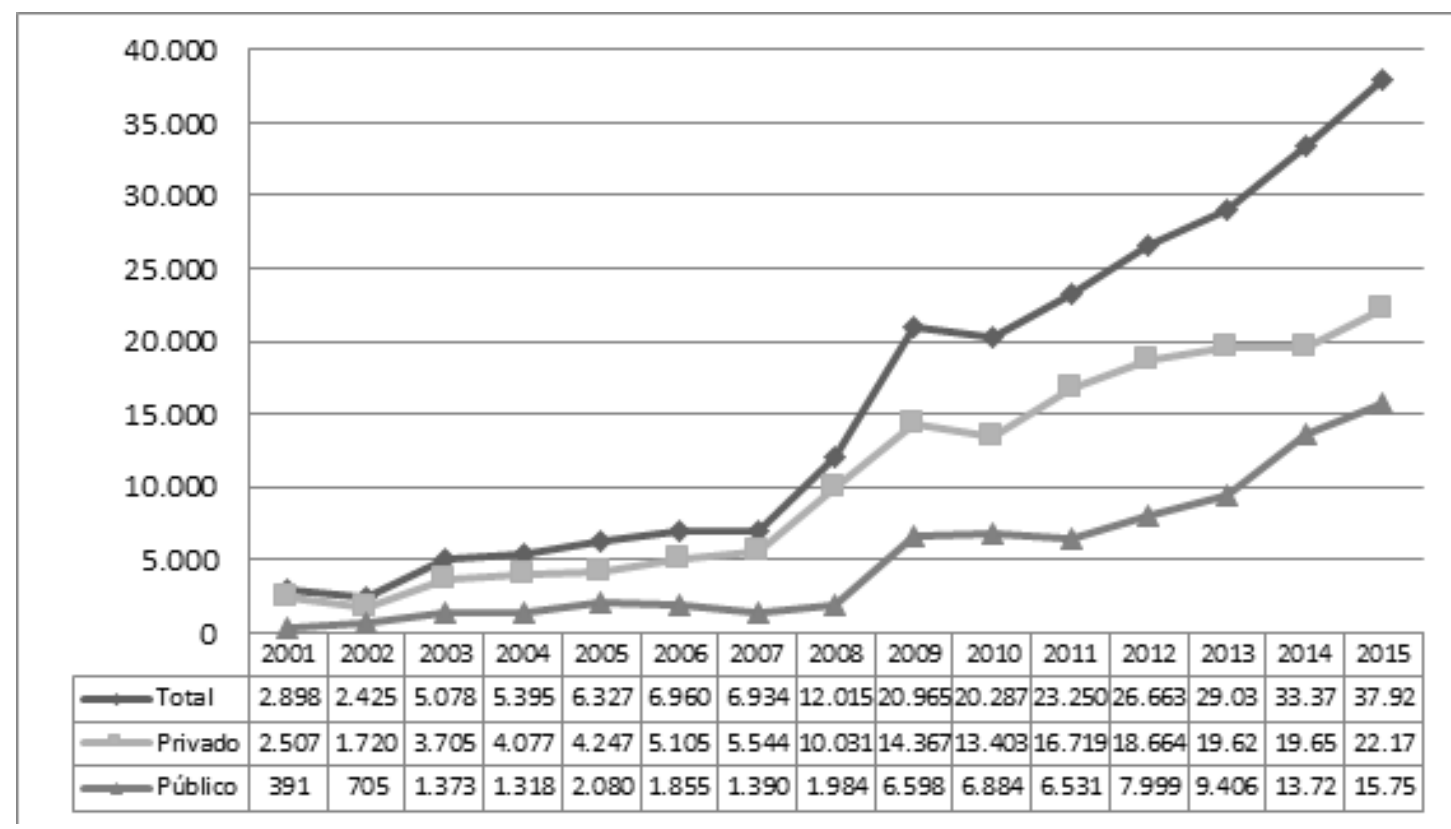

Figura 1. Evolução das matrículas de alunos com deficiência nas instituições de educação superior brasileiras de 2001 a 2015 segundo dados do INEP. 


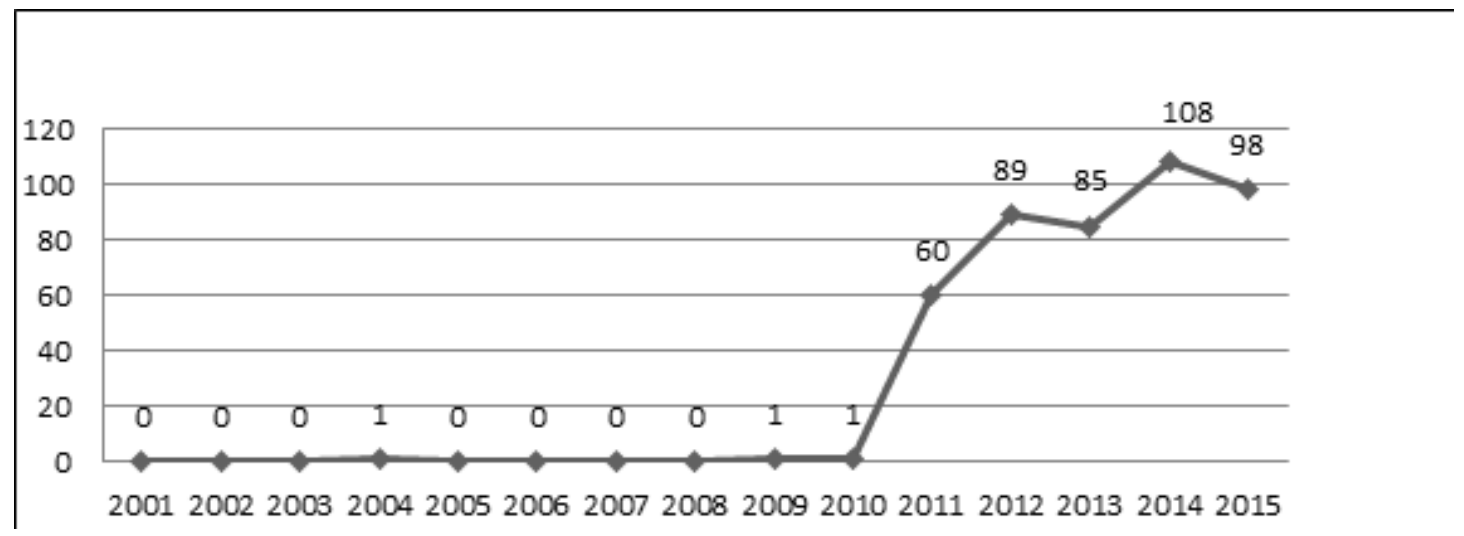

Figura 2. Evolução das matriculas de alunos com deficiência nos cursos de graduação da UFJF no período de 2001 a 2015 segundo dados do INEP e CAEFI/UFJF.

Nos últimos anos, observamos movimentos importantes visando à ampliação de vagas por meio de políticas públicas específicas como o REUNI e o PROUNI ${ }^{3}$, e a implementação de um sistema de cotas nas instituições públicas de educação superior reservando $50 \%$ de suas vagas para estudantes com baixa renda e para autodeclarados pretos, pardos e indígenas de forma proporcional ao número destes sujeitos na população da unidade da Federação onde está instalada a instituição (Lei no 12.711, 2012). Porém, somente em dezembro de 2016 foram incluídas nesta reserva de vagas, as pessoas com deficiência por meio da Lei N. ${ }^{\circ} 13.409 / 2016$ (2016).

Analisando então a produção destes números, assim como Reis (2010), podemos demonstrar que os dados disponibilizados pelo INEP apresentam inconsistência em relação à matrícula de alunos com deficiência. Isso porque, ao nos aprofundarmos sobre o processo de produção desses números na UFJF, identificamos que até o momento da implantação da sua coordenação de acessibilidade (CAEFI/ UFJF), não havia mecanismos institucionais para identificação desses alunos, mesma dificuldade relatada por Anache, Rovetto e Oliveira (2014) em outra instituição de educação superior. No caso da UFJF, sem uma identificação intra-institucional, estes ficaram ausentes dos relatórios enviados ao INEP até a criação do primeiro mecanismo de autodeclaração por parte da CAEFI/UFJF no ano de 2011, como pode ser visto na figura acima:

Vale pontuar que os dados do Censo da Educação Superior são coletados a partir do preenchimento de questionários por parte das instituições e por importação dos dados disponibilizados pelas mesmas no Sistema e-MEC, de

3 O Programa de Apoio a Planos de Reestruturação e Expansão das Universidades Federais (REUNI) tem como principal objetivo ampliar o acesso e a permanência na educação superior a partir de uma série de ações visando a expansão física, acadêmica e pedagógica da rede federal de educação superior (Decreto $\left.n^{\circ} 6.096,2007\right)$. Já o Programa Universidade para Todos (PROUNI) foi criado pelo MEC em 2005 para conceder bolsas de estudo integrais e parciais de $50 \%$ em cursos de graduação e sequenciais de formação específica ministrados em instituições privadas a estudantes brasileiros sem diploma de nível superior (Lei no 11.096, 2005). forma que é de responsabilidade da instituição de educação superior o levantamento dos dados referentes ao seu corpo discente (INEP, 2017).

O levantamento dos registros de alunos com deficiência da UFJF foi iniciado pela CAEFI/UFJF no ano de 2011 utilizando como metodologia o fechamento do Sistema Integrado de Gestão Acadêmica (SIGA), usado por todos os alunos no período de matrícula e rematrícula discente e ao longo de todo o seu processo formativo. Através de um plug, o SIGA pergunta a cada aluno da UFJF se ele possui ou não deficiência, apresentando as opções "sim" e "não". O sistema só é reaberto após a resposta e, caso positiva, um questionário é aplicado ao aluno autodeclarado com deficiência. A partir desse mecanismo, os alunos autodeclarados com deficiência puderam ser identificados, ter seus dados tabelados e submetidos ao Sistema e-MEC, passando então a vigorar nos relatórios oficinas do INEP.

Movimento análogo é observado nas demais instituições de educação superior, que passaram a buscar a identificação de seus alunos com deficiência a partir do momento em que os padrões de acessibilidade se tornam requisito avaliativo para sua autorização, reconhecimento e credenciamento (Portaria n 3.284, 2003), e principalmente, a partir do Programa Incluir, que confere recursos para a criação e consolidação de núcleos de acessibilidade nas instituições federais de educação superior (Brasil, 2013).

Podemos assim considerar que o sistema de cotas, apesar de já praticado por algumas universidades brasileiras, tem uma contribuição ainda pequena no aumento do número de alunos com deficiência matriculados na educação superior. A maior influência advém de um interesse crescente pela identificação destes sujeitos no corpo discente, inclusive por força das políticas públicas. Nos cabe agora questionar os sentidos que este aumento numérico tem junto ao processo de inclusão.

\section{Inclusão como presença}


Pensando que os dados numéricos, enquanto informações quantitativas das ciências exatas carregam a força de uma verdade ao serem compreendidos como representação fiel do real, um levantamento estatístico se constitui como um discurso que carrega a força da legitimidade, sendo pouco questionável e portando o direito de avaliar os processos sociais. Estes sentidos são mobilizados especialmente em dados com os do INEP, já que são utilizados para o direcionamento da política pública educacional brasileira enquanto representação da realidade social de nosso país. Dessa forma, a inclusão somente passa a ser reconhecida quando a presença dos alunos com deficiência se faz notar nos números do INEP. É através desses números que dizemos que a inclusão é hoje existente nas escolas básicas e na educação superior.

Porém, enquanto discurso construído que mantém relação com o interdiscurso e é sujeito à ação da ideologia, os números carecem de interpretação, pois mobilizam sentidos. Não podemos esquecer que o discurso só existe por causa do sujeito e que os sentidos são fluidos, porém, constituídos em uma materialidade sócio-histórica (Pêcheux, 2009).

Nessa perspectiva, interpretar a inclusão enquanto presença não é um movimento de sentidos unicamente presente no discurso produzido pelas estatísticas oficiais, mas este também reverbera nos sujeitos da educação superior. Observe os recortes abaixo:

A24 - ...eu não sei se é porque eu não vejo... muitas pessoas com... não que elas não tenham deficiência mas assim, que seja fácil de identificar...

C21 - Nós temos aqui pouquíssimos casos de pessoas em estado de deficiência, os casos que nós temos a gente, pelo menos no meu ponto de vista, nós soubemos... é... lidar com relativa tranquilidade..

D01 - Eles estão aparecendo mais também. A gente tinha uma dificuldade muito grande de... que eles até respondessem o e-mail da gente, que aparecesse quando a gente chamasse. Ainda não está cem por cento, mas está encaminhando.

D28 - Os alunos vêm/ muitas vezes eles... se escondem em um primeiro momento dentro da universidade. Aí, de repente, tem um problema, eles vão e procuram a CAEFI pela primeira vez...

O sujeito da educação superior, seja ele com deficiência ou não, avalia o processo de inclusão a partir da presença do aluno com deficiência. Aqui, não por uma presença numérica como nos dados do INEP, mas por um reconhecimento cotidiano, relacionado à identificação deste outro em suas atividades diárias na universidade.

Observe que os sujeitos A24 e C21 indicam conhecer poucos alunos com deficiência na UFJF, enquanto os sujeitos D01 e D28, por atuarem diariamente com pessoas com deficiência na CAEFI/UFJF, sabem da existência destes sujeitos, mas pontuam a falta de autoidentificação dos mesmos. Um silenciamento constitutivo da relação estabelecida entre o sujeito-aluno com deficiência e os demais sujeitos da educação superior, de forma a não se identificarem enquanto aluno com deficiência para o outro e/ou para a universidade.

A05 - Os desafios? ... Acho que... o deficiente... se aceitar como deficiente, porque eu também tive um pouquinho de dificuldade de me aceitar como deficiente.

A09 - Então, na verdade... é só para quem eu falo. Para quem eu não.../ visualmente, eu não tenho nada... eu não tenho nada.

C19 - Primeiro, descobrir que ela tinha deficiência, porque a A18 é tão boa aluna, ela é tão aplicada, tão interessada, que eu demorei a perceber que ela tinha.

Este processo de silenciamento reflete, inclusive, nas estatísticas oficiais produzidas pela CAEFI/UFJF e que compõem os dados do INEP:

D28 - ...porque o nosso questionário ele é respondido de maneira voluntária, então você que se identifica como deficiente ou não, então, muitas vezes ele não coloca nada, você nem sabe que aquela pessoa existe. Ele tem um problema, ele aparece.

Para a Análise de Discurso, o sujeito assume no discurso uma posição imbuída de sentidos e valores, e é a partir dessa posição-sujeito que ele estabelece relações com outros sujeitos e interpreta os discursos (Orlandi, 2013). Quando o sujeito com deficiência assume a posição-sujeito de aluno universitário, este vivencia uma tensão entre se reconhecer com os sentidos de descrédito relacionados à deficiência e com os sentidos de valor relacionados à educação superior, gerando contradições em se autodeclarar ou não enquanto sujeito-aluno com deficiência:

A11 - Aqui dentro da universidade nunca tive problema com preconceito, até porque eu sempre fui muito... é... muito discreto, e a deficiência só é perceptível se eu quiser mostrar, se eu não quiser mostrar ninguém percebe.

A12 - Alguns sabem, outros não. Porque assim, não atrapalha no dia a dia.

A13 - Até na minha própria família sempre rolou isso ai, essa situação de tipo: "Não, você não é deficiente", "Não, para com isso. Não fala isso". Não é como se fosse uma coisa negativa, entendeu? É só uma.... [procura palavras] uma coisa diferente...

A29 - Eu me sinto talvez um... sei lá... um pária, um diferente, mas é porque eu tenho esse problema mesmo. 
Observe que os discursos não apenas caracterizam a deficiência, mas criam um comparativo, uma dualidade, entre o sujeito com deficiência e um sujeito ideal. Este sujeito ideal, normatizado e sem deficiência, não atende as singularidades que constituem o universo da deficiência e nem mesmo da diversidade da espécie humana, contudo, possui força de verdade e de valor graças à sua constituição sócio-histórica (Fernandes, 2012). Pelo apagamento realizado pela ideologia, o padrão de sujeito ideal é constituído como evidência. Nele a deficiência não se adéqua, seja ela de qual tipo for.

Portanto, o silenciamento no questionário é sintomático de uma postura já adotada no cotidiano deste sujeito, que busca se desvincular da deficiência como forma de proteção contra o preconceito, por conta dos sentidos de estigma, de menos valia, a ela relacionados (cf. Goffman, 2008).

Quando silencia a sua condição de deficiência, o sujeito fica apagado tanto das estatísticas oficias quanto do reconhecimento de suas necessidades. Esse silenciamento acarreta na não promoção da acessibilidade em suas múltiplas dimensões, especialmente pelo desconhecimento da instituição e dos demais sujeitos para realizar este atendimento.

Tal prática se filia ao paradigma integracionista discutido por Sassaki (1999), e exemplificado por Selau e Damiani (2014) ao contar parte da história do primeiro advogado cego formado no Brasil na década de 1950. Neste paradigma, assim como ocorreu com o advogado,a pessoa com deficiência é a responsável pela sua inclusão, galgando espaços e direitos por méritos individuais, sem requerer nenhuma modificação por parte da sociedade e de suas instituições.

Sendo a inclusão interpretada apenas como presença, tendemos a mobilizar sentidos de que o simples direito de acesso seria suficiente para promovê-la na educação superior, apagando as singularidades dos alunos com deficiência e desconsiderando as barreiras à sua permanência, deixando de promover adequações necessárias à sua participação em igualdade de condições.

\section{Inclusão como provimento de acessibilidade}

Em contradição a estes sentidos, a inclusão tem sido significada pelos pesquisadores da área e em políticas públicas mais recentes, como a promoção de condições de acesso e permanência em igualdade de condições, especialmente sob o prisma de promoção da acessibilidade.

Segundo Massmann (2014), o conceito de acessibilidade, que inicialmente esteve atrelado ao sentido de criar condições de mobilidade no espaço urbano, foi sendo aplicado também ao espaço digital-informacional. Mais ainda, passou a receber contribuições de outras áreas do saber, ampliando seus sentidos para dar conta de questões referentes à comunicação, conforto, segurança e autonomia das pessoas em geral, não apenas para as pessoas com deficiência (Lippo, 2012b).
De acordo com esta perspectiva e buscando abranger diferentes exigências para que a acessibilidade contemple o conjunto das relações sociais ao ir além dos espaços construídos, dos transportes e das comunicações, Sassaki (2011) propõe que a acessibilidade seja constituída por seis dimensões: (1) Arquitetônica, relacionada à eliminação de barreiras ambientais físicas nos espaços urbanos, nos edifícios e no transporte coletivo; (2) Comunicacional, que trata de possibilitar a comunicação nos seus diversos suportes; (3) Metodológica, que aborda a flexibilização dos métodos e técnicas de estudo, trabalho e produção; (4) Instrumental, que visa a flexibilização no uso de instrumentos e ferramentas de estudo, trabalho e lazer; (5) Programática, que se ocupa da eliminação de políticas públicas, normas e regulamentos que possam criar barreiras à inclusão; (6) Atitudinal, que exige a eliminação de preconceitos, estigmas e estereótipos socialmente instituídos.

O atendimento a estas dimensões é, portanto, constitutivo do movimento de inclusão social, no qual a sociedade se mobiliza para subsidiar a participação de todas as pessoas em condição de igualdade nos espaços sociais, independentemente de suas características individuais, pois como nos diz Ferreira (2014), a inclusão em uma perspectiva diversa é assegurar e dar condições de permanência bem sucedida, com respeito, equiparação e conhecimento.

Em relação ao sujeito-aluno com deficiência, este pode necessitar de diferentes dimensões da acessibilidade dependendo de suas características funcionais, como pode ser observado no estudo de Rocha e Miranda (2009) e no de Mendes e Bastos (2016). Contudo, identificamos que este sujeito tende a significar a inclusão principalmente enquanto acessibilidade arquitetônica, sendo esse sentido recorrente em sujeitos com todos os tipos de deficiência:

A06 - Essas construções e essa engenharia hoje, essa estrutura hoje... que é ensinada, é apenas normativa e essa normativa, ela não passa por um empírico. Não passa. Não passa pela minha experiência.

A07 - ...a gente sabe que passando por um momento de crise, corte de verbas, mas tem coisa que é essencial, entendeu? Tem que dar manutenção aos elevadores.

A10 - Bom... em questão de espaço é... horrivel... A FAEFID é totalmente... não é preparada para receber deficiente. Tanto, sei lá... todos os momentos que eu passei aqui de muleta, não consegui andar em lugar certo pra muleta.

A15 - Tem algumas dificuldades ainda, na infraestrutura também, você viu ali o elevador também... Acabou de ver que não funciona, né?

A30 - Eu vejo assim, eu posso ainda subir uma escada e descer com uma lentidão, mas tem gente que não pode. Elevadores, tem hora que não estão funcionando, entendeu? 
Observe que a mobilização de substantivos relacionados à acessibilidade arquitetônica como sinônimo de inclusão não está restrita unicamente ao sujeito-aluno com deficiência:

B26 - ...eu não acho que tenha rampas para subir para o segundo andar. Acho que tinha até um elevador, que é o que eu sei, só que esse elevador não funciona.

B32 - Eu vejo só rampa e calçada. Fora isso,... a maioria dos pisos daqui são inadequados, né? Tem prédios aqui sem elevador...

C31 - Aqui é um instituto de difícil acesso, por causa da escada...

D02 - A gente precisa de obra e as coisas não acontecem.

Como evidenciam Rocha e Miranda (2009), Anache, Rovetto e Oliveira (2014) e Mendes e Bastos (2016), as adequações arquitetônicas nas instituições de educação superior ainda são incipientes e, frequentemente, constituem dificuldades à inclusão do aluno com deficiência, portanto, há uma materialidade nestes sentidos relacionada a dificuldades reais no cotidiano universitário.

Contudo, nos chama a atenção a reiteração da acessibilidade exclusivamente pelo sentido arquitetônico por sujeitos sem deficiência e por sujeitos que possuem deficiência sensorial ou intelectual e que não dependem deste tipo de adequação. Podemos então considerar que, sendo o conceito de acessibilidade inicialmente cunhado no sentido de adequação arquitetônica (cf. Lippo 2012a; Massmann, 2014), este se mantém como sentido estabelecido para a acessibilidade.

Isso se soma ao fácil reconhecimento da existência da deficiência física e da materialização de algumas condições de sua inclusão: "engenharia", "estrutura", "elevador", "escada", "espaço", "rampa", "piso", "obra". Observe que todos estes termos foram mobilizados nos recortes acima como sinônimos de inclusão, como mecanismo para avaliar se esta existe ou não na universidade. Tal processo perpassa ainda o pouco conhecimento relativo ao universo da deficiência e das múltiplas dimensões da acessibilidade.

Ao mobilizar o sentido de acessibilidade arquitetônica, a inclusão cria o sujeito com deficiência que se espera ser incluído: com deficiência física e com comprometimentos na locomoção. Isso não significa que os sujeitos entrevistados pensem na inclusão como exclusividade para pessoas com este tipo de deficiência, mas que seu discurso restringe a promoção da acessibilidade para estes sujeitos.

Contudo, se a inclusão mantiver como modelo-padrão de sujeito com deficiência aquele que possui uma determinada deficiência e com uma funcionalidade corporal específica, há de perpetuar a promoção da exclusão, pois os processos de acessibilidade produzem sentidos. Este equívoco, ao invés de deslocar a norma que constitui as relações sociais atualmente - objetivo este dos processos de acessibilidade segundo Lippo (2012b) - pode simplesmente ampliar o tipo de sujeito que se adéqua ao modelo-padrão idealizado pela sociedade, perpetuando a exclusão.

\section{Considerações finais}

Pensar a diversidade humana em oposição aos modelos socialmente estabelecidos de ser humano ideal é um desafio para a sociedade contemporânea. Incluir pessoas com deficiência nos múltiplos espaços sociais exige um movimento de adequação que não passa apenas pelo direito de acesso ou pela promoção da acessibilidade arquitetônica, mas sim por uma modificação do modelo-padrão de ser humano idealizado para os espaços e relações sociais. Desestabilizar as normas e os padrões sócio-historicamente estabelecidos é a tarefa do atual processo de inclusão.

Visando o avanço deste processo, destacamos a necessidade de um olhar mais atento aos sentidos mobilizados pela deficiência no sujeito, pois como demonstramos em relação aos dados do INEP, o não reconhecimento da posição-sujeito de aluno universitário com deficiência é sintomático do preconceito e da estigmatização ainda atreladas à deficiência, e influencia diretamente na identificação e no atendimento de suas necessidades individuais para eliminação das barreiras que concorrem com sua inclusão.

Indicamos assim a necessidade de revisão nos modelos atuais de levantamento de dados sobre a presença de alunos com deficiências nas instituições de educação superior brasileiras, levando em consideração o processo de reconhecimento individual enquanto sujeito-aluno com deficiência. Pontuamos ainda a necessidade de ampliar o conhecimento relativo à promoção da acessibilidade em suas múltiplas dimensões, de forma que esta não seja restrita a dimensão arquitetônica.

Mais ainda, é necessário desestabilizar os sentidos de desvalorização, de anomia atrelados à deficiência e a demais signos de estigma, a fim de favorecer a constituição de um aluno universitário diverso, não ideal, que abarque a diversidade constitutiva da espécie humana em uma sociedade plural e inclusiva.

\section{Referências}

Anache, A.A.; Rovetto, S.S.M.; Oliveira, R.A. (2014). Desafios da implantação do atendimento educacional especializado no Ensino Superior. Revista Educação Especial, 27 (49), 299-312.

Brasil. Ministério da Educação/ Secretaria de Educação Especial (2007). Política nacional de educação especial na perspectiva da educação inclusiva. Brasília, DF: MEC. Recuperado: 02 jan. 2017. Disponível: http://portal.mec.gov.br/seesp/arquivos/pdf/politica. pdf.

Brasil. Ministério da Educação/ Secretaria de Educação Continuada, Alfabetização, Diversidade e Inclusão / Secretaria 
de Educação Superior (2013). Documento orientador: Programa Incluir - Acessibilidade na Educação Superior. Brasília, DF: MEC. Recuperado: 02 jan. 2017. Disponível: http://portal. mec.gov.br/index.php?option=com_docman\&task $=$ doc_ download\&gid $=12737 \&$ ltemid $=$.

Castro, S.F.; Almeida, M.A. (2014). Ingresso e Permanência de Alunos com Deficiência em Universidades Públicas Brasileiras. Revista Brasileira de. Educação Especial, 20(2), 179-194.

Chauí, M. (2003). A universidade pública sob nova perspectiva. Revista Brasileira de Educação, (24), 5-15.

Decreto $n^{\circ}$ 6.096, de 24 de abril de 2007 (2007, 24 de abril). Institui o Programa de Apoio a Planos de Reestruturação e Expansão das Universidades Federais - REUNI.Brasília, DF: Diário Oficial [da República Federativa do Brasil].Recuperado: 02 jan. 2017. Disponível: http://www.planalto.gov.br/ccivil_03/_ato2007010/2007/decreto/d6096.htm

Decreto $n^{\circ}$ 6.949, de 25 de agosto de 2009 (2009, 25 de agosto). Promulga a Convenção Internacional sobre os Direitos das Pessoas com Deficiência e seu Protocolo Facultativo, assinados em Nova York, em 30 de março de 2007. Brasília, DF: Diário Oficial [da República Federativa do Brasil]. Recuperado: 02 jan. 2017. Disponível:http://www.planalto.gov.br/ccivil_03/_ato20072010/2009/decreto/d6949.htm.

Elias, N. (1993). O processo civilizador: formação do Estado e civilização ( $2^{\circ}$ vol.). Rio de Janeiro: Zahar.

Fernandes, I. (2012). Relações sociais no convívio com as diferenças e deficiências numa perspectiva histórica. In: Lippo, H. (Org.), Sociologia da acessibilidade e reconhecimento político das diferenças (pp. p. 17-31). Canoas: ULBRA.

Ferreira, E.L. (2003). Corpo-movimento-deficiência: as formas dos discursos da/na dança em cadeira de rodas e seus processos de significação. Tese de Doutorado, Faculdade de Educação Física, Universidade Estadual de Campinas, Campinas, SP.

Ferreira, E.L. (2014). Educação Física: em busca de uma nova resignificação. In: Ferreira, E.L.; Orlandi, E.P. (Orgs.), Discursos sobre a inclusão (pp.270-286). Niterói: Intertexto, 2014.

Goffman, E. (2008). Estigma: notas sobre a manipulação da identidade deteriorada (4a. ed.). Rio de Janeiro: LTC.

Instituto Nacional de Estudos e Pesquisas Educacionais Anísio Teixeira [INEP] (2015). Sinopses Estatísticas da Educação Superior - Graduação. Recuperado: 02 jan. 2017. Disponível: http://portal.inep.gov.br/web/guest/censo-da-educacao-superior.

Instituto Nacional de Estudos e Pesquisas Educacionais Anísio Teixeira [INEP] (2017). Censo da Educação Superior. 2017. Recuperado: 02 jan. 2017. Disponivel: http://portal.inep.gov.br/ web/censo-da-educacao-superior.
Lei no 11.096, de 13 de janeiro de 2005 (2005, 13 de janeiro). Institui o Programa Universidade para Todos - PROUNI, regula a atuação de entidades beneficentes de assistência social no ensino superior; altera a Lei o 10.891, de 9 de julho de 2004, e dá outras providências. Brasília, DF: Diário Oficial [da República Federativa do Brasil]. Recuperado: 02 jan. 2017. Disponível: http://www. planalto.gov.br/ccivil_03/_ato2004-2006/2005/lei/L11096.htm.

Lei $n^{\circ}$ 12.711, de 29 de agosto de 2012 (2012, 29 de agosto). Dispõe sobre o ingresso nas universidades federais e nas instituições federais de ensino técnico de nível médio e dá outras providências. Brasília, DF: Diário Oficial [da República Federativa do Brasil. Recuperado: 02 jan. 2017. Disponível: http://www.planalto.gov.br/ ccivil_03/_ato2011-2014/2012/lei//12711.htm.

Lei $n^{\circ}$ 13.146, de 06 de julho de 2015 (2015, 06 de julho). Institui a Lei Brasileira de Inclusão da Pessoa com Deficiência (Estatuto da Pessoa com Deficiência). Brasília, DF: Diário Oficial [da República Federativa do Brasil]. Recuperado: 02 jan. 2017. Disponível:http:// www.planalto.gov.br/ccivil_03/_Ato2015-2018/2015/Lei/L13146. htm.

Lei $n^{\circ}$ 13.409, de 28 de dezembro de 2016 (2016, 28 de dezembro). Altera a Lei no 12.711, de 29 de agosto de 2012, para dispor sobre a reserva de vagas para pessoas com deficiência nos cursos técnico de nível médio e superior das instituições federais de ensino. Brasília, DF: Diário Oficial [da República Federativa do Brasil]. Recuperado: 02 jan. 2017. Disponível: http://www.planalto. gov.br/ccivil_03/_Ato2015-2018/2016/Lei/L13409.htm\#art1.

Lippo, H. (2012a). Introdução. In: Lippo, H. (Org.), Sociologia da acessibilidade e reconhecimento político das diferenças(pp. 1114). Canoas: ULBRA.

Lippo, H. (2012b). Para um conceito de acessibilidade. In: Lippo, H. (Org.), Sociologia da acessibilidade e reconhecimento político das diferenças (pp. 75-85). Canoas: ULBRA.

Massmann, D. (2014). Acessibilidade: sentidos em movimento. In: Ferreira, E.L.; Orlandi, E.P. (Orgs.), Discursos sobre a inclusão(pp. 191-224). Niterói: Intertexto.

Mendes, H.S.F.; Bastos, C.C.B.C. (2016). Um estudo sobre a realidade da inclusão de pessoas com deficiência na educação superior no Paraná. Revista Educação Especial, 29 (54), 189-202.

Oliveira, J.F. (2013). Acesso à educação superior no Brasil: entre o elitismo e as perspectivas de democratização. In: Sousa, J.V. (Org.), Educação superior: cenários, impasses e propostas (1a. ed., pp. 1-27). Campinas, SP: Autores Associados.

Organização das Nações Unidas para a Educação, a Ciência ea Cultura [UNESCO] (1998a). Declaração mundial sobre educação para todos: satisfação das necessidades básicas de aprendizagem. Jomtien: UNESCO. Recuperado: 02 jan. 2017. Disponível: http:// 
unesdoc.unesco.org/images/0008/000862/086291por.pdf.

Organização das Nações Unidas para a Educação, a Ciência ea Cultura [UNESCO] (1998b). Declaração de Salamanca sobre princípios, política e práticas na área das necessidades educativas especiais. Salamanca: UNESCO. Recuperado: 02 jan. 2017. Disponível: http://unesdoc.unesco.org/images/0013/001393/139394por.pdf.

Orlandi, E.P. (2001). Discurso e texto: formulação e circulação de sentidos. Campinas, SP: Pontes.

Orlandi, E.P. (2012). Discurso em análise: sujeito, sentido e ideologia (2a. ed.). Campinas, SP: Pontes.

Orlandi, E.P. (2013). Análise de discurso: princípios e procedimentos (11a. ed.). Campinas, SP: Pontes.

Pêcheux, M. (2009).Semântica e discurso: uma crítica à afirmação do óbvio (4a. ed.). Campinas, SP: UNICAMP.

Portaria $n^{\circ} 3.284$, de 7 de novembro de 2003 (2003, 7 de novembro). Dispõe sobre requisitos de acessibilidade de pessoas portadoras de deficiências, para instruir os processos de autorização e de reconhecimento de cursos, e de credenciamento de instituições. Brasília, DF: MEC. Recuperado: 02 jan. 2017. Disponível: http:// portal.mec.gov.br/seesp/arquivos/pdf/port3284.pdf.

Reis, N.M.M. (2010). Política de inclusão escolar de pessoas com necessidades educacionais especiais no ensino superior e as universidades federais mineiras. Dissertação de Mestrado, Programa de Pós-Graduação Conhecimento e Inclusão Social, Universidade Federal de Minas Gerais, Belo Horizonte, MG.

Rocha, T.B.; Miranda, T.G. (2009). Acesso e permanência do aluno com deficiência na instituição de ensino superior. Revista Educação Especial, 22 (34), 197-212.

Sassaki, R.K. (1999). Inclusão: construindo uma sociedade para todos(3a. ed.). Rio de Janeiro: WVA.

Sassaki, R.K. (2011) Acessibilidade na inclusão escolar e laboral. In: Ferreira, E.L. (Org.), Atividades físicas inclusivas para pessoas com deficiência (2a. ed., vol. 3). Niterói: Intertexto.

Selau, B.; Damiani, M.F. (2014). Quando não se falava em inclusão: a história de vida do primeiro advogado cego formado no Brasil. Revista Educação Especial, 27 (49), 417-430.

Silva, O.M. (1987). A epopéia ignorada: a pessoa deficiente na história do mundo de ontem e de hoje. São Paulo: Cedas.

License information: This is an open-access article distributed under the terms of the Creative Commons Attribution License (type CCBY), which permits unrestricted use, distribution and reproduction in any medium, provided the original article is properly cited.

Recebido em: 22/08/2017 Aprovado em: 07/11/2017

\section{Sobre os autores}

José Guilherme de Andrade Almeida (almeida.jga@gmail.com)

Licenciado e bacharel em Educação Física pela Universidade Salgado de Oliveira (2011 e 2012). Especialista em Pesquisa Científica pela UFJF (2014). Mestre em Educação pela UFJF (2016). Professor da Secretaria Municipal de Educação de São Gonçalo - RJ; pesquisador e professor do Grupo de Pesquisa em Inclusão, Movimento e Ensino à Distância (N-GIME). Programa de Pós-Graduação em Educação - Universidade Federal de Juiz de Fora. Juiz de Fora - MG.

https://orcid.org/0000-0003-4789-6126

Eliana Lucia Ferreira (eliana.ferreira@ufjf.edu.br)

Pós-doutorado em Avaliação Educacional do Ensino pela Universidade Nacional do Ensino a distância - UNED-Espanha (2012); Pós-doutorado em Linguística com ênfase em Análise de discurso pela UNICAMP (2008). Doutorado e mestrado em Educação Física pela UNICAMP. Professora Efetiva Associada do Departamento de Fundamentos da Faculdade de Educação Física (UFJF) e Professora do Programa de Pós-Graduação em Educação (UFJF). Juiz de Fora - MG.

https://orcid.org/0000-0001-7978-8731 